\title{
Chapter 13 \\ Supporting Mathematical Learning \\ Processes by Means of Mathematics \\ Conferences and Mathematics Language \\ Tools
}

\section{Christoph Selter and Daniel Walter}

\begin{abstract}
In recent decades, the instructional theory of Realistic Mathematics Education has exerted a powerful influence on mathematics education around the world. The idea of progressive mathematisation has gained international acceptance. In this chapter, we will illustrate the way in which we benefited from the idea of organising the teaching and learning of mathematics in keeping with this guiding principle. After some personal memories of the first author, we start by describing what we consider to be the central elements of the principle of progressive mathematisation. This is followed by a description of two methods, the mathematics conferences and mathematics language tools, for rendering the learning and teaching concepts entailed by the principle of progressive mathematisation-especially its vertical component-even more expedient and fruitful. The contribution concludes with an explanation of how we understand the term 'realistic' in Realistic Mathematics Education.
\end{abstract}

Keywords Progressive schematisation - Mathematics conferences $\cdot$ Language and mathematics $\cdot$ Individual learning processes $\cdot$ Co-operative learning $\cdot$ Mathematics language tools

\subsection{The Santa Claus Problem}

It must have been at the end of 1983 that the first author-at the time studying to become a primary school teacher-became aware of Adri Treffers' paper "Fortschreitende Schematisierung - ein natürlicher Weg zur schriftlichen Multiplikation und Division im 3. und 4. Schuljahr" (Treffers, 1983). Taking the multiplication of large

\footnotetext{
C. Selter ( $\square)$

Faculty for Mathematics/IEEM, TU Dortmund, Dortmund, Germany

e-mail: christoph.selter@math.tu-dortmund.de

D. Walter

Faculty for Mathematics, Münster University, Münster, Germany

e-mail: daniel.walter@uni-muenster.de 


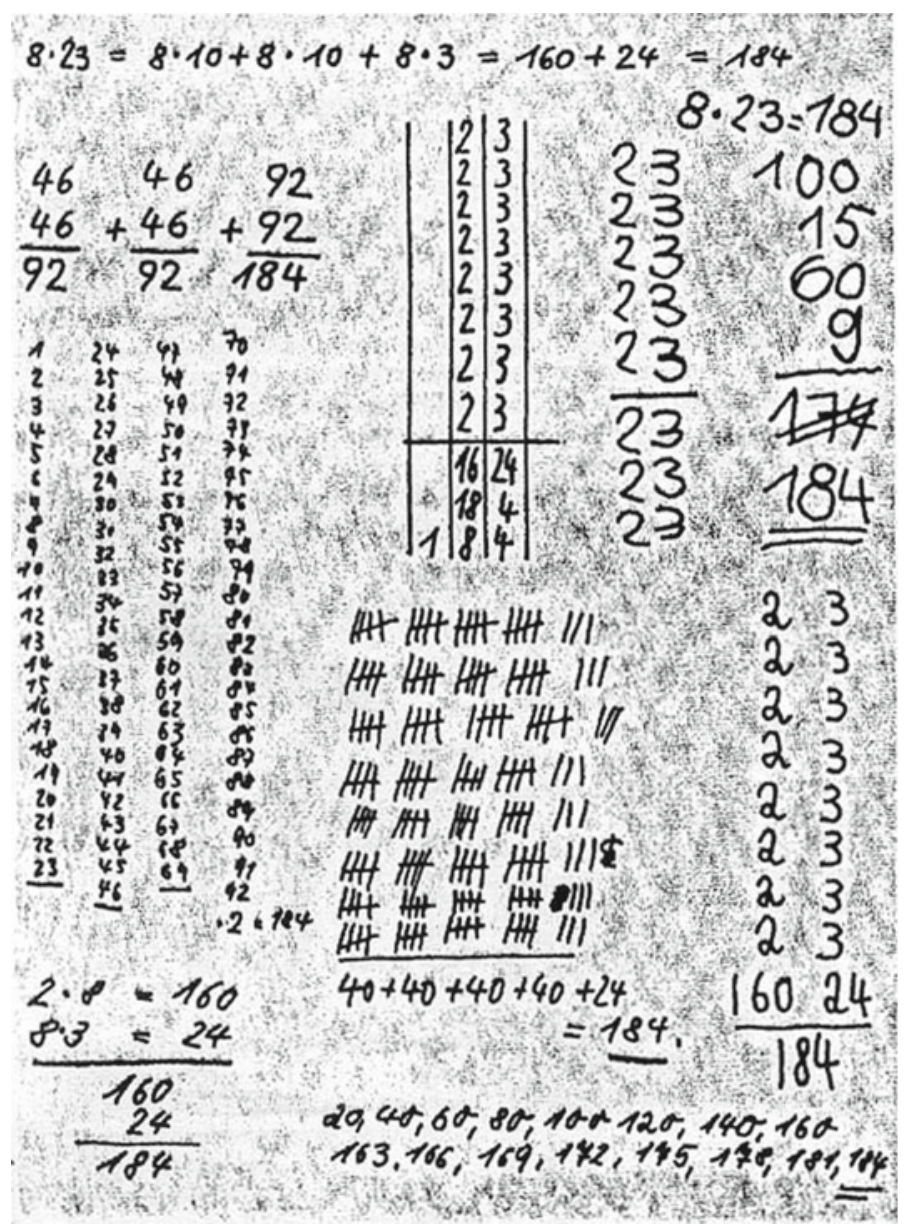

Fig. 13.1 Solutions to the Santa Claus problem

numbers as an example, this paper describes how students can be motivated to apply their individual approaches and develop them further in a purposeful manner. The starting question in the paper is: "Santa Claus has his gifts distributed in the village by eight helpers. Each has 23 parcels. How many parcels do they have altogether?"

Treffers' paper describes how eight-year-old students solved this problem using strategies they had individually developed in various ways (Fig. 13.1). The strategies naturally differed in terms of elegance and efficiency (Treffers, 1993), and therewith either represent the stages observable in the development of a single child or the heterogeneity noticeable within a learning group of students. The 'Santa Claus' problem serves as a representative example for illustrating a possible starting point of the so-called 'principle of progressive mathematisation'. 
Starting from problems like this one, the various solution strategies of the students are discussed, explained, and elaborated in interactions between the students or between the teacher and the students. The students can see how other students work and thereby assess the advantages and disadvantages of different strategies (Treffers, 1991). An individual student's (mental) actions are as vitally important as his or her interaction with other students. The illustrations included in the paper are taken from a lesson where the students were not shown how to solve this type of problem based on the principles of isolating difficulties and increasing complication-as was still widespread in use in the classrooms of that time-but instead by encouraging them to develop their own approaches and then also develop them further. To put it briefly: from inventions to conventions.

Reading Treffers' paper was a key event for the first author because he realised that the principle of progressive schematisation-or progressive mathematisation, as it should preferably be called - is by no means only important for learning written calculation algorithms, but could also be considered a comprehensive, generally applicable principle for the organisation of mathematical learning or teaching processes. In the German speaking countries, within the didactics of mathematics for primary schools, progressive mathematisation is nowadays considered a guiding principle (Krauthausen \& Scherer, 2007).

The principle of progressive mathematisation has naturally also undergone specific adaptations and further developments in Germany. This chapter is meant to report on them. To do this, it starts in Sect. 13.2 with a description of what the central elements of the principle of progressive mathematisation are in our opinion. Then we describe methods for making teaching/learning processes that follow the principle of progressive mathematisation even more expedient and productive.

As conversations amongst students are often not automatically task-specific and efficient, it is an important task for the teacher to stimulate and organise exchanges amongst the learners that will promote learning. In this respect, we describe the method of so-called 'mathematics conferences' in Sect. 13.3. As students occasionally find it difficult to verbalise the description and justification of mathematical facts and contexts, it is also necessary to provide them with tools for further developing their ability to express themselves in words. In this context, Sect. 13.4 describes the so-called 'mathematics language tools'. Our chapter concludes with comments on how we understand the term 'realistic' in Realistic Mathematics Education (RME).

\subsection{The Guiding Principle of Progressive Mathematisation}

Mathematics classes and the didactical research and development dedicated to them around the world have been inspired by the conception of RME for over four decades. This development arose from the dissatisfaction with the understanding of teaching and learning predominant in the 1960s. In the Netherlands (and not only there), mathematics was reduced to its formal character in an atomised manner, leading to an overemphasis on its structuralist aspects. Teachers taught the procedures demonstra- 
tively step-by-step, whereupon the students exhibited inflexible and reproductionbased knowledge (Van den Heuvel-Panhuizen \& Drijvers, 2014).

The efforts revolving around RME and its influence on an international level laid one of the cornerstones of the constructivistic informed understanding of teaching and learning mathematics established nowadays internationally (see, e.g., Verschaffel, Greer, \& De Corte, 2007; Wittmann, 2005).

Starting from Freudenthal's (1968) claim that mathematics is a human activity, the core principle of RME is that formal mathematical knowledge can be derived from students' thinking (Treffers, 1993). Learners should learn to mathematise, that is "the organising and structuring activity during which acquired knowledge and abilities are called upon in order to discover still unknown regularities, connections, structures" (Treffers, 1987, p. 247). The core principle of RME is that mathematics can be developed from personal reality. That means that formal knowledge can be developed from students' thinking (Treffers, 1993). This process should be natural and the students should contribute to the teaching/learning process as much as possible. To this end, five basic keystones have been formulated for the principle of progressive mathematisation (see, e.g., Streefland, 1990):

- Learning is a (re)constructive activity stimulated by concreteness; teaching involves the use of problems that can be realised by students (thus 'realistic' does not necessarily mean real-life).

- Learning is a long-term process moving from concreteness to abstraction; teaching involves globally guiding students from their informal, context-bound strategies to formal mathematics.

- Learning is facilitated by reflection on one's own thought processes and those of others; teaching involves encouraging students to look back and to reflect on the teaching/learning process.

- Learning is always embedded in a socio-cultural context; thus, teaching involves opportunities for communication and cooperation as in small group work or wholeclass discussion.

- Learning is the construction of knowledge and skills to a structured entity; teaching involves intertwining different learning strands.

Besides these five overarching characteristics, the principle of progressive mathematisation has two interlocking components, that is, vertical and horizontal mathematisation: "In the horizontal component the way towards mathematics is paved via model formation, schematising, symbolising. The vertical sketch is concerned with mathematical processing and level raising in the structuring of the problem field under consideration" (Treffers, 1987, p. 247).

Horizontal mathematisation is hence described as a bridge from the real world to formal symbolic mathematics, while vertical mathematisation concerns activities within the formal symbolic realm. It is meanwhile of decisive importance that a student will only be enabled to reach a higher level of mathematics (Gravemeijer \& Doorman, 1999) by way of vertical mathematisation which, amongst other aspects, includes activities devoted to reorganising, economizing and linking numerical structures (see Van den Heuvel-Panhuizen, 2002). 
The distinction between horizontal and vertical mathematisation, also known as "two-way mathematisation" (Van den Heuvel-Panhuizen, 2010, p. 3), fundamentally contributes to our understanding of the RME concept while also distinguishing it from other learning and teaching approaches (see, e.g., Streefland, 1991; Treffers, 1987; Van den Heuvel-Panhuizen, 2010). There should nevertheless be no sharp distinction between horizontal and vertical mathematisation activities. That horizontal and vertical mathematisation processes can dovetail is part and parcel of the RME theory (Treffers, 1993). "The distinction between horizontal and vertical mathematizing depends on the specific situation, the person involved and his environment" (Freudenthal, 1991, p. 42).

Although RME hence attaches great value to the theoretical equality of horizontal and vertical mathematisation, there have also been phases in the development of RME where there was a tendency to focus on engaging with questions of horizontal mathematisation (see Treffers 1993; Van den Heuvel-Panhuizen, 2002). Even today, the research into vertical mathematisation appears to be paid less attention in international mathematical didactics than is the case with horizontal mathematisation (see Glade \& Prediger, 2017). Therefore, the focus in this chapter will be on aspects of vertical mathematisation.

Nevertheless, it should be emphasised that the principle of progressive mathematisation in its horizontal and vertical component is paid a great deal of attention in Germany, as mentioned above. Progressive mathematisation is repeatedly referred to in research and development papers published by staff of the Institute for Development and Research in Mathematics Education in Dortmund (IEEM) (Akinwunmi, 2012; Glade, 2016; Link, 2012), and also in projects such as PIKAS ${ }^{1}$ and KIRA, ${ }^{2}$ which contribute to the professionalisation of teachers. This is also where further developments and adaptations to German education take place. In this chapter, we report about two adaptations of vertical mathematisation: mathematics conferences and mathematics language tools. The examples have been taken from the PIKAS project.

\subsection{Using Mathematics Conferences}

\subsubsection{Learning to Subtract in the Number Domain up to 1000}

Based on Sundermann and Selter (2012) and as a further development of Selter (1998), a concrete implementation for subtraction in the domain up to 1000 is to be described first. The third graders involved in the PIKAS project were, from their experiences in the previous school year, already familiar with various ways of calcu-

\footnotetext{
1 pikas.dzlm.de (website in German).

2 kira.dzlm.de (website in German).
} 
Table 13.1 Possible calculation strategies

\begin{tabular}{l|l|l}
\hline Pair of problems & Standard calculation & A clever calculation could be \\
\hline $68-25$ and $568-325$ & $68-25$ & $568-325$ \\
& $68-20-5$ & $500-300=200$, so 243 \\
& Jump strategy & Analogy strategy \\
or & $60-20=40$ & \\
& $8-5=3$ & \\
& $40+3=43$ & \\
& Split strategy & \\
\hline $72-46$ and $872-546$ & Jump strategy or & Analogy strategy \\
$95-32$ and $795-432$ & Split strategy & \\
\hline $61-26$ and $761-226$ & Jump strategy or & $60-25$ or $760-225$ \\
& Split strategy & Adjustment strategy \\
\hline $71-68$ and $471-468$ & Jump strategy or & $68+\ldots 71$ or \\
$92-87$ and $792-587$ & Split strategy & $587+=592,+200$ \\
& & Determining the difference \\
\hline $142-99$ and $642-299$ & Jump strategy or & $142-100+1$ or \\
$171-98$ and $871-398$ & Split strategy & $871-400+2$ \\
& & Auxiliary problem \\
\hline
\end{tabular}

lating in the domain up to 100 . Now they were challenged in three activities of each several teaching hours to expand the number domain to 1000 .

In the first activity, "This is how I calculate!-How do you calculate?", the students were asked to document how they calculate specific problems. To this end, the students were provided with various problems which, at least from the perspective of experienced calculators, each suggested one particular calculation strategy, based on the numbers involved (Table 13.1). ${ }^{3}$

The task given was: "Calculate as cleverly as possible! Write down your calculation strategies so that other children can understand them." The students were furthermore encouraged to explain their calculation strategy and justify why they had done it this way. Finally, they were asked to give their calculation strategy a name, because this would raise their awareness of how different the various calculation strategies are, and ease their communication about the various strategies.

Ronja's work (Fig. 13.2) shows that she recognised that the tens and ones of the minuend and subtrahend are close together. She calculated all the problems by turning the minuend into a round number using subtraction, then she performed the subtraction that is now easier for her to do, and finally she applied a compensation operation by adding the ones of the minuend again. At the top section of the worksheet (Fig. 13.3) the students were asked to initially think about a possible calculation strategy. Ronja noticed that in the case of $71-68$, the minuend is close to a ten.

The students initially worked on the task on their own, with the teacher providing individual support. Then they were encouraged to form mathematics conferences,

\footnotetext{
${ }^{3}$ For more information on the various calculation strategies, see kira.dzlm.de/062.
} 


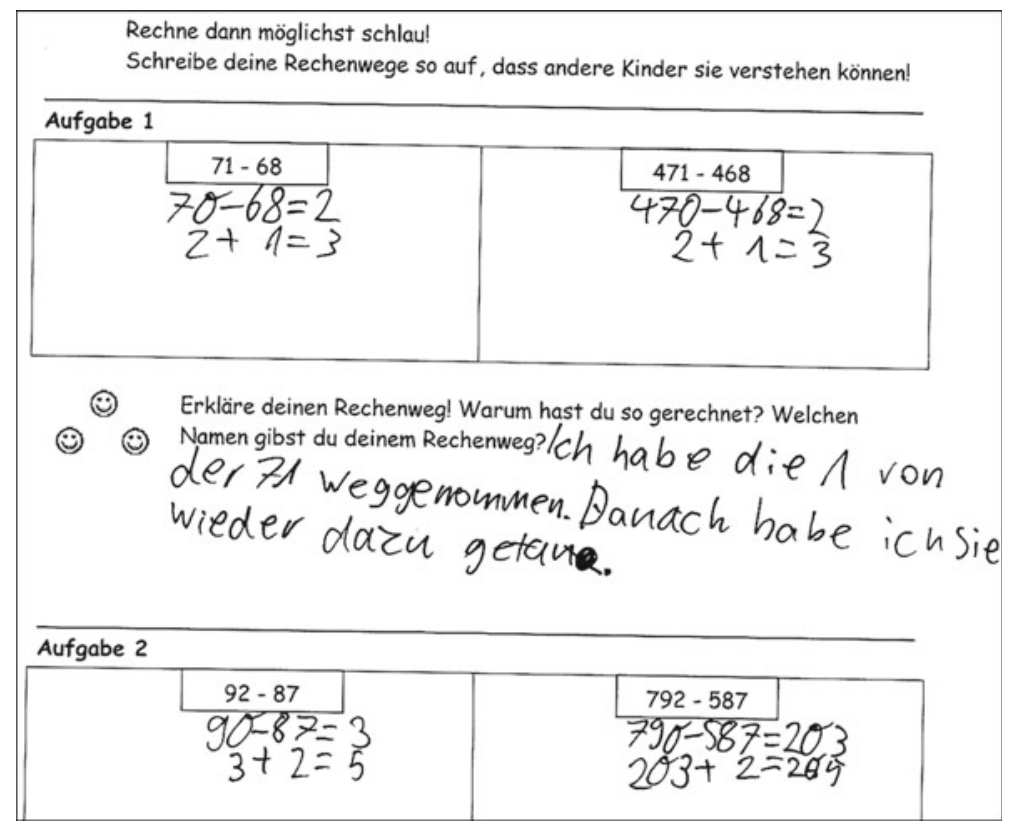

Fig. 13.2 Ronja's work (Translation: try to calculate as cleverly as possible! Write down your way of calculation so that other children can understand it!; Explain your way of calculation! Why did you calculate like that? What name do you give your way of calculation? Ronja: "I took away 1 from the 71. Subsequently I added it again.")

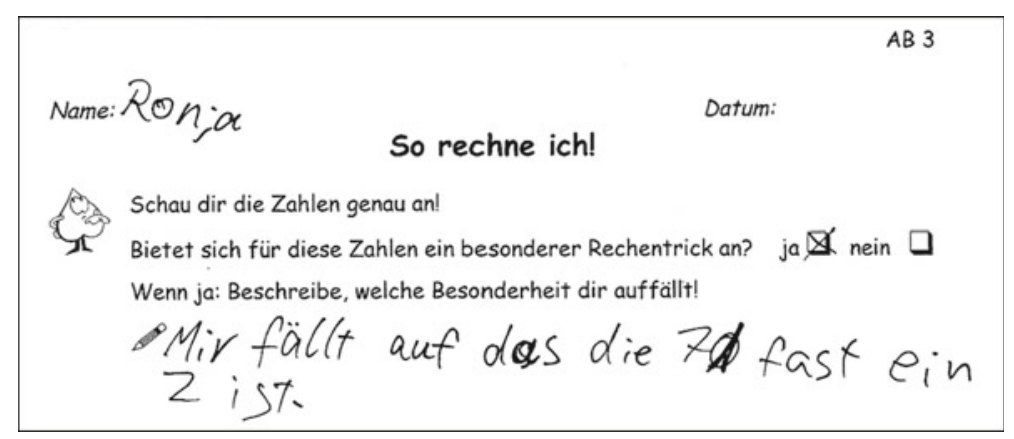

Fig. 13.3 Top section of the work sheet (Translation: take a close look at the numbers. Does a particular calculation trick suggest itself for these numbers? If yes, please describe the special thing that you notice. Ronja: "I notice that 71 is almost a ten.") 
Table 13.2 Problems for Activity 3

\begin{tabular}{l|l|l}
\hline Problem & Standard calculation & A clever calculation could be \\
\hline $864-243$ & $\begin{array}{l}864-200-40-3 \\
\text { Jump strategy or } \\
800-200=600\end{array}$ & - \\
& $\begin{array}{l}60-40=20 \\
4-3=1\end{array}$ & \\
& $600+20+1$ & \\
& Split strategy & $546-200+2$ \\
\hline $546-198$ & $\begin{array}{l}\text { Jump strategy or } \\
\text { Split strategy }\end{array}$ & Auxiliary problem \\
\hline $917-458$ & $\begin{array}{l}\text { Jump strategy or } \\
\text { Split strategy }\end{array}$ & - \\
\hline $672-668$ & $\begin{array}{l}\text { Jump strategy or } \\
\text { Split strategy }\end{array}$ & $668+\ldots=672$ \\
& & Determining the difference \\
\hline
\end{tabular}

a method we will describe in greater detail below, for communicating about their calculation strategies. The results of these conferences were finally presented to the entire class, attended by a discussion of why certain strategies can be cleverer than others, depending on the numerical values.

The second activity, titled "We calculate the way other children calculated", was aimed at sensitizing the students to the variety of possible calculation strategies. First, the students were involved in actively applying the various clever strategies of other students, and then they were asked to rate the strategies. The goal of the activity was not that children master all strategies. However, they should have the opportunity to encounter each of them.

Figure 13.4 again shows Ronja's work, who initially copied the strategy (a jump strategy with the help of the empty number line) applied by her classmate Jenny and then rated it as very clever. In the end, the special characteristics of the individual calculation strategies were reflected upon with the students, while also highlighting in which cases each strategy might be particularly clever. The exchange stimulated justifications why particular strategies suggested themselves for the particular problems (dependent on the numbers involved) and gave students the opportunity to identify and name less clever calculation strategies.

The third activity, titled "We calculate as cleverly as possible!", was focused on the independent grading and assessing of students' own strategies and those of others in terms of efficiency. Thanks to the various numbers used in the problems, each problem suggested a specific calculation strategy (Table 13.2).

The students were also allowed to follow their own preferences here again (if possible, with giving a reason for this). The worksheets below illustrate that the students were sensitised to the variety of possible calculation strategies by trying them out, and they were also increasingly better able to name them (Fig. 13.5). 


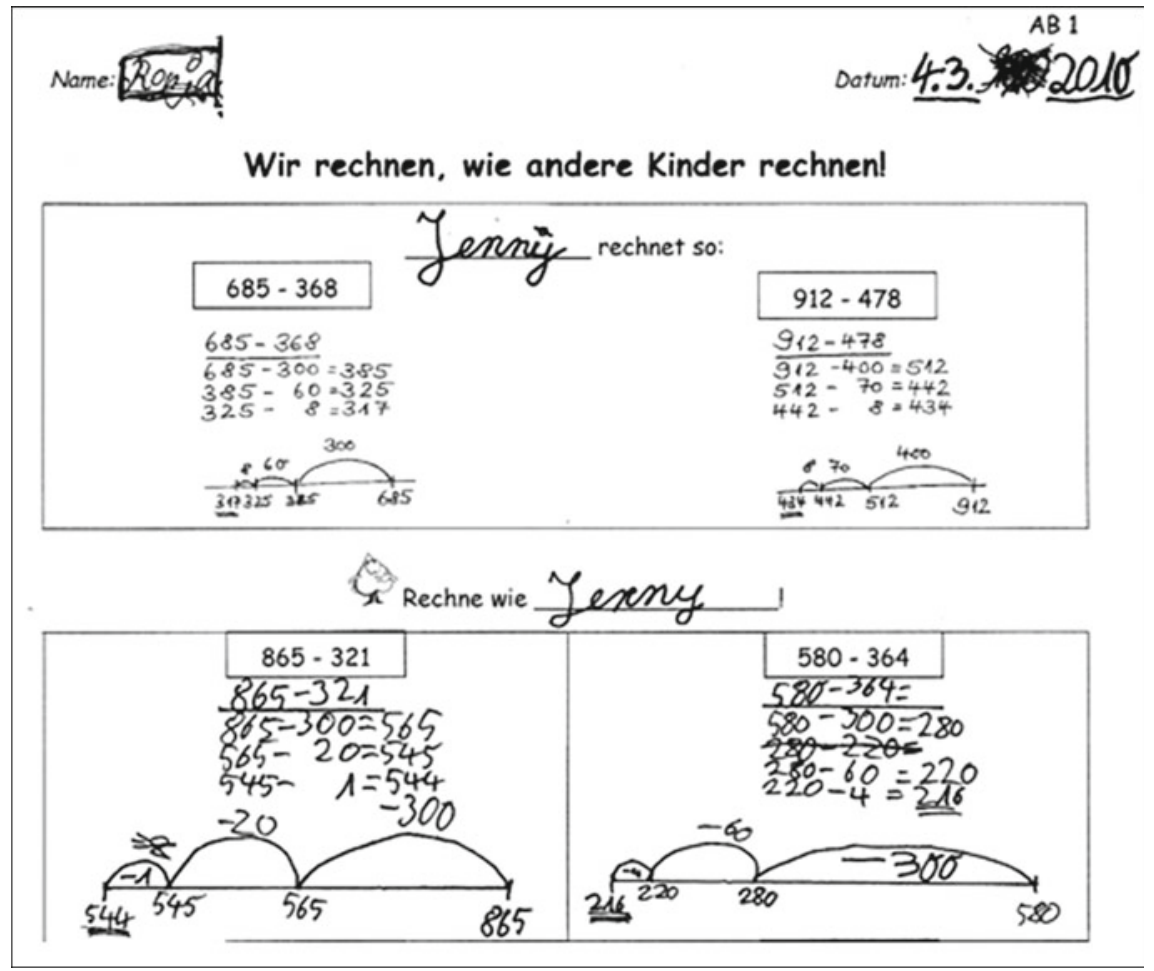

Fig. 13.4 Ronja's work (Translation: We calculate the way other children calculate. Jenny calculated in this way. Calculate like Jenny.)

The students initially worked on their own. Lara-Maria described her approach with the help of Dienes blocks. She also confirmed the statement that for $864-243$ a particular calculation strategy suggested itself. She justified this as follows:

All the numbers (i.e., digits) of the first number are greater than those of the second number, which is why one can easily subtract the hundreds from the hundreds, the tens from the tens and the ones from the ones.

For the second problem she noted:

The one number is very close to the next hundred, which is why one can very easily apply the change-trick.

She indicated with arrows how she converted the $546-198$ problem into $548-200$.

Afterwards, the students were asked to communicate in mathematics conferences with their classmates about their calculation strategies and give reasons why they thought their calculation strategy was clever. In the end, the students wrote for one or several problems a note about a so-called 'particularly clever strategy'. This note 


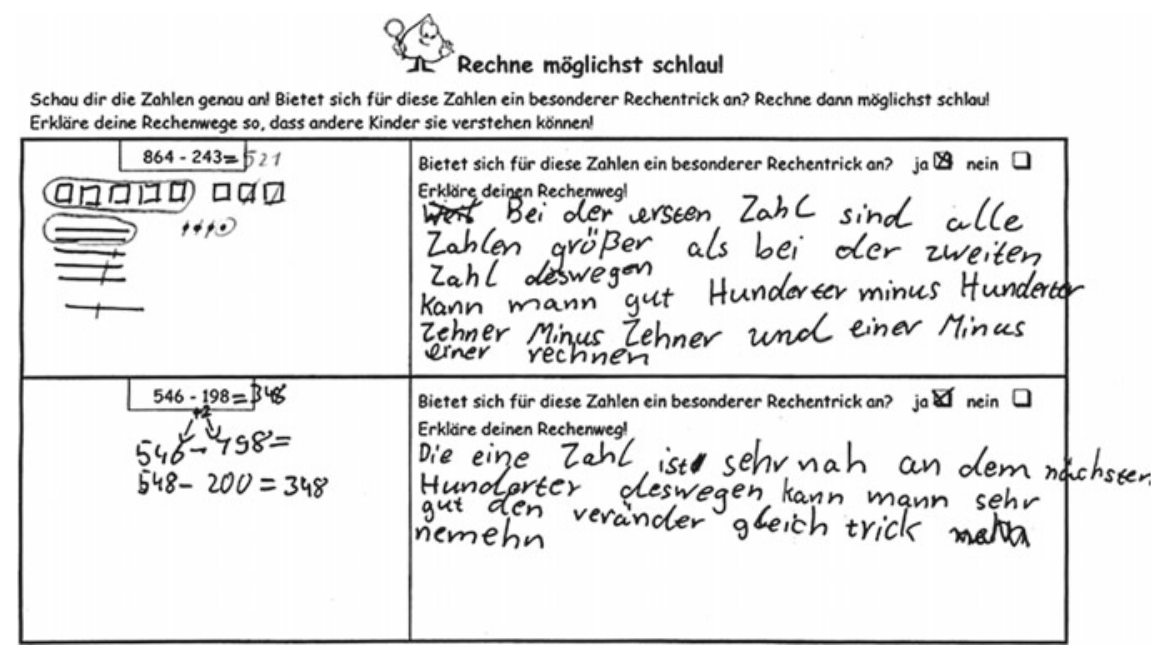

Fig. 13.5 Lara-Maria's work (Translation of the instruction: Look at the numbers! Does a particular calculation trick come into your mind for these numbers? Then, calculate as cleverly as possible! Write down your calculation strategies so that other children can understand them.)

was meant to be discussed in class in the reflection phase. In this phase, individual students or group of students could visualise, explain and justify their results by putting their notes on the board underneath the corresponding problem.

\subsubsection{Task-Related Exchange with the Help of Mathematics Conferences}

In the activity previously described, the task-related discussion between the students in mathematics conferences acted as a central activity for joint learning (see also, Anders \& Oerter, 2009; Götze, 2007; Sundermann, 1999). A mathematics conference is understood as a meeting of students in which in small (heterogenic) groups individual solution strategies of students are presented and reflected on (see Sundermann $\&$ Selter, 1995). However, this does not mean that all teamwork can immediately be called a mathematics conference. Important is that the students are challenged to describe and justify their approach to solving a problem, to explain their discoveries, and to follow the thought processes of the other students.

This task-related exchange benefits all students, so the mathematics conference has a dual function. On the one hand the students who act as an author (author-student) benefit by verbalising their own thought processes and attempting to present them understandably. On the other hand, students who are the listeners (listener-student), are simultaneously actively involved as well by being asked to trace and compare 
the approaches of the students who describe their strategies. In this way, they can provide the author-students criteria-led feedback.

In contrast to having only a reflection phase in a whole-class setting, this form of cooperation in small groups steps up the verbal involvement (and engagement with the posed problem) of the individual student and also offers weaker and less communicative students a chance to speak. Of course, organising mathematics conferences will not render the reflection phase in the whole-class setting superfluous. Discussions in whole-class remain important. The mathematics conferences with the small groups can be a particularly good preparation for them. By having the backing of their small group quieter students will possibly be encouraged to articulate their thoughts here as well.

Mathematics conferences can already be introduced from the first year of school. The essential requirement for making this method successful is the quality of the problem that is used. The problem needs to be demanding enough and should permit various ways of thinking and solving it, so that an exchange is also meaningful from the perspective of the students.

\subsubsection{Tools for Organising Mathematics Conferences}

The ability to take part in mathematics conferences, which means being able to explain your own results and approaches, and to understand the ideas and solution strategies of others, will not come about in the students all by itself. Like any other method, a mathematics conference also needs to be introduced to become a common method in class. Providing students with an overview poster, titled "Solving mathematics problems together" (see Fig. 13.6) can help them to become familiar with this method. The guideline makes a distinction in three phases.

In Phase 1 (the I-phase) the students have enough time for their individual work and for describing their own solution strategy, so that they will be able to engage in an exchange about their approach afterwards. They write down their thoughts about solving the problem and then try to present them in a manner that the other students can understand. When a student has completely solved and understandably explained the given problem from his or her perspective or possibly wants to have support from the other students, he or she registers for the mathematics conference by writing down his or her name in a list that is displayed in the classroom on paper or on the blackboard. As soon as three students - as a rule-have registered, they convene for a mathematics conference. The exchange can begin as soon as the group has come together in a quiet place.

In Phase 2 (the You-phase) a joint elaboration of guiding questions is recommended in order to prevent mathematics conferences from ending up in an unstructured stringing together of information or to avoid that students get lost in details. The structuring can be provided by the poster titled "Tips for the mathematics conference" (Fig. 13.7) available to the students. The tips subdivide the progress of 


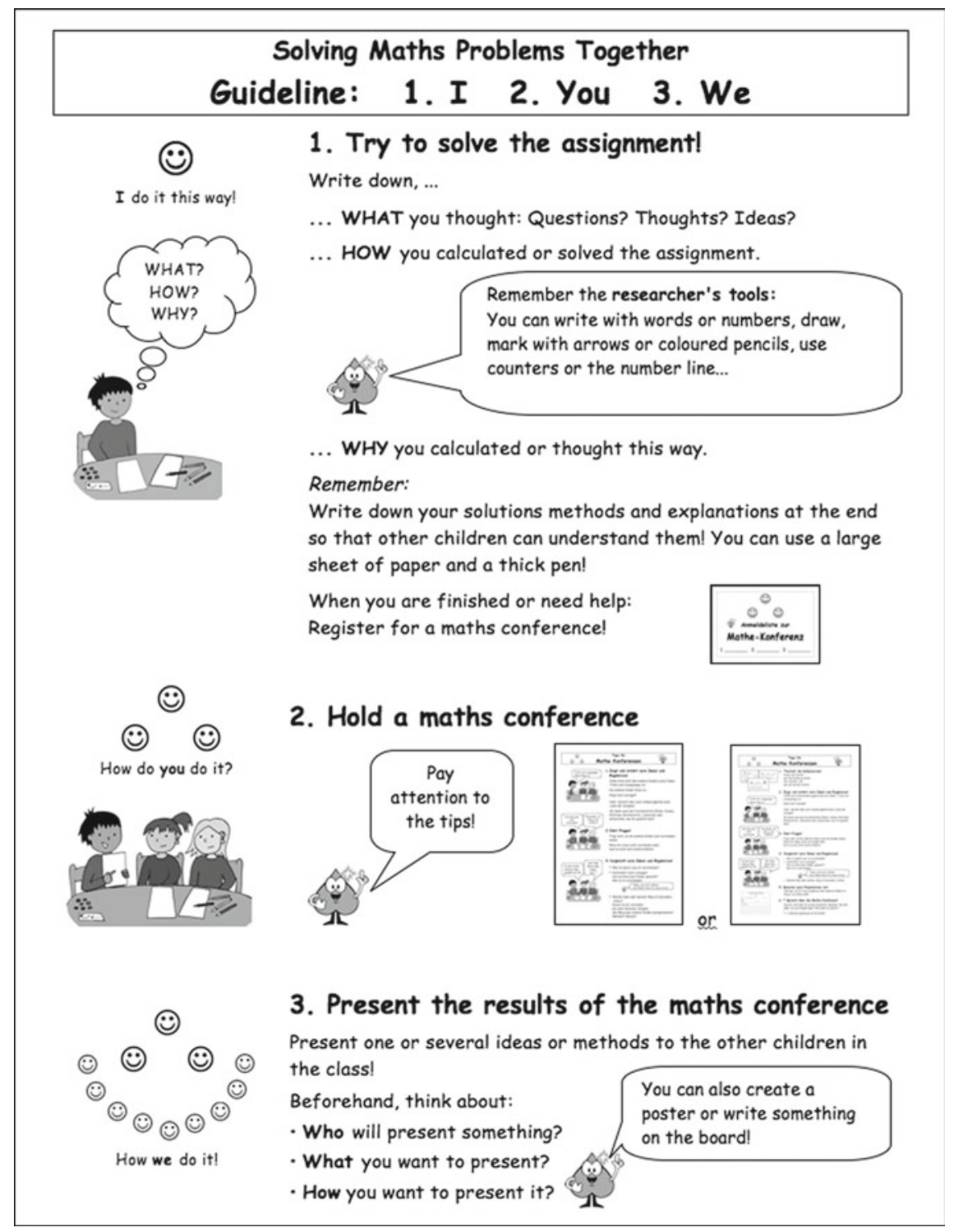

Fig. 13.6 Mathematics conference guideline (translated from German by the authors) 


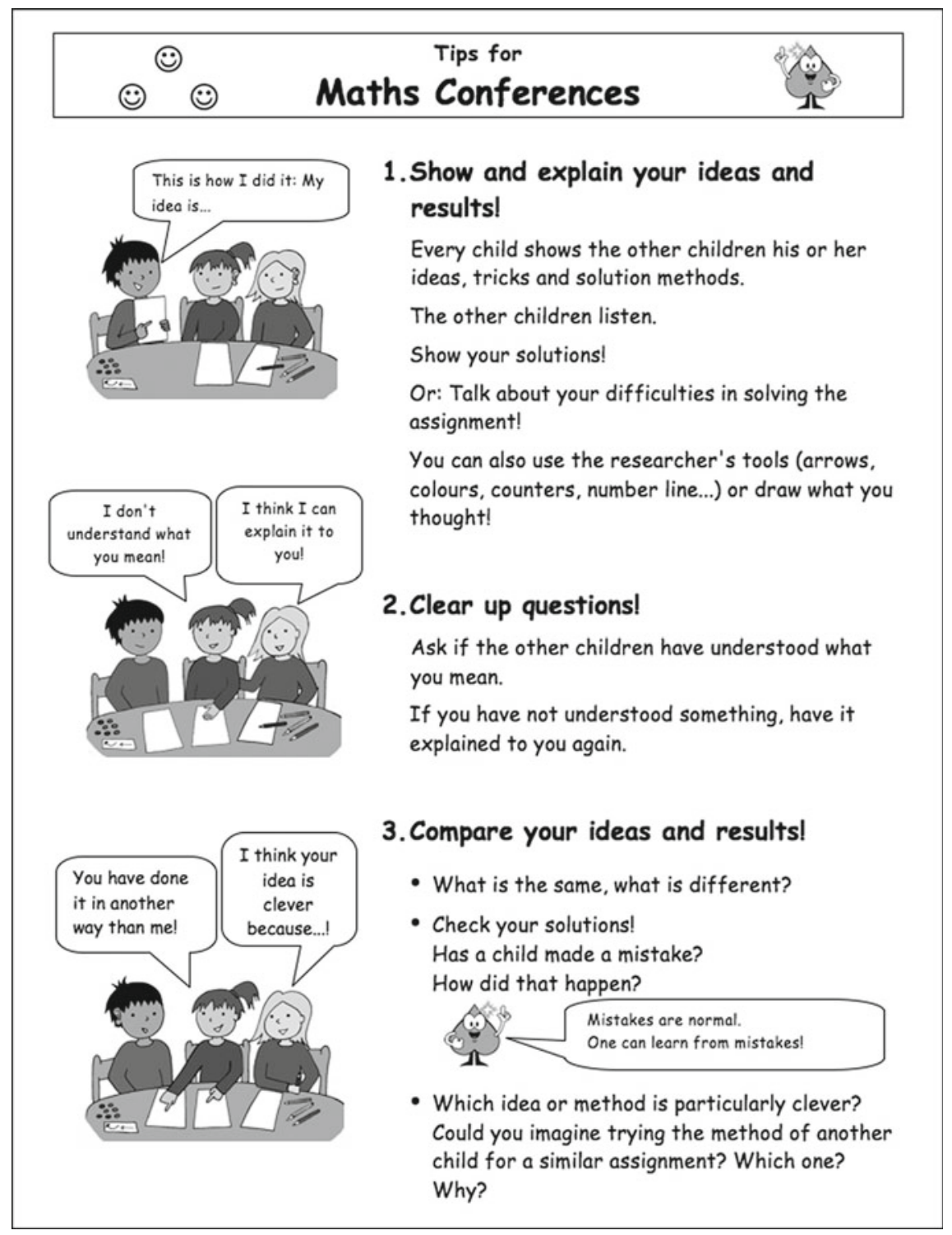

Fig. 13.7 Tips for mathematics conferences (translated from German by the authors)

the mathematics conference into several sections and thus furnish the students with orientation aids and examples for possible guiding questions:

- How has the author-student solved the problem?

- Why did he or she proceed in this way?

- Is the attempt at explanation by the author-student understandable? 
- Is the selected approach clever?

- Who has chosen another route? What is different about it?

$-\ldots$

If asking these kinds of guiding questions has become a natural habit of the students, this habit can contribute to structuring the conversation and hence to students' learning from each other. The questions can deliberately direct the students' attention from their individual approaches to other ways of looking at things, and can stimulate a critical and constructive questioning of the solution strategies amongst the students.

Although the responsibility for a mathematics conference is largely in the hands of the students, adequate support by the teacher is nonetheless of vital importance. The teacher, in the role of moderator, can keep the conversation going and cognitively activate the students by way of targeted interventions. In this way, the teacher contributes to the constructive progress of the mathematics conference.

If the students are not yet used to discuss their solution strategies in mathematics conferences, it can be helpful for students to reflect upon this method with other students at a meta level. An advantageous way to do this is the so-called 'fishbowl'. This means that a group of volunteers who were just about to start a mathematics conference moves to the centre of a circle of chairs. In addition to the chairs provided for

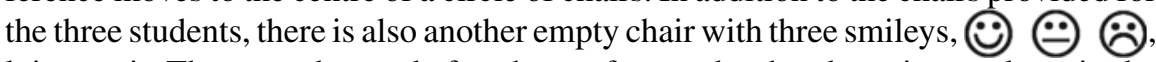
lying on it. These can be used after the conference by the observing students in the outer circle to indicate constructive (method-related or content-related) feedback ("I liked that everyone was allowed to finalise his/her speaking" or "I find that your solution strategy is not so clever because....") and/or for giving tips ("If you also used arrows or colours in the description of your discovery packages, the other students could probably understand that better"). To ensure that discussion rules are complied, the student providing feedback is going to sit down on the empty chair.

In Phase 3 (the We-phase) the evaluation of the process and the reflection upon the results of the discussion can be finally presented in the whole-class setting. The questions formulated in the overview poster (see Fig. 13.6) about the organisation of this presentation will urge the students to prepare it in a as structured and targetoriented manner as possible.

\subsection{Learning to Describe and Explain by Using Mathematics Language Tools}

This section is dedicated to describing a second adaptation of the RME approach, the so-called 'mathematics language tools'. Before starting this description, we should make clear the importance that mathematics language has in German mathematics teaching as reflected in the German mathematics curricula. In the nation-wide education standards of the Standing Conference of Ministers of Education and Cultural Affairs (KMK, 2004), start from the assumption that learning mathematics involves 
(a)

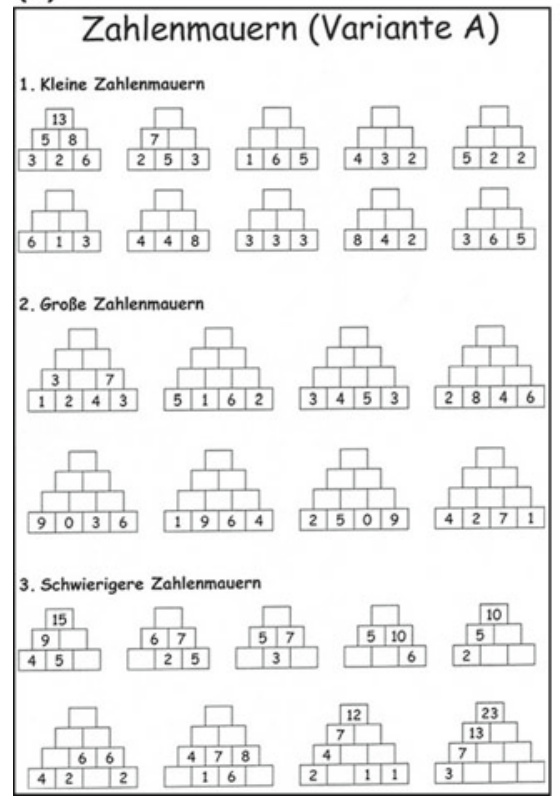

(b)

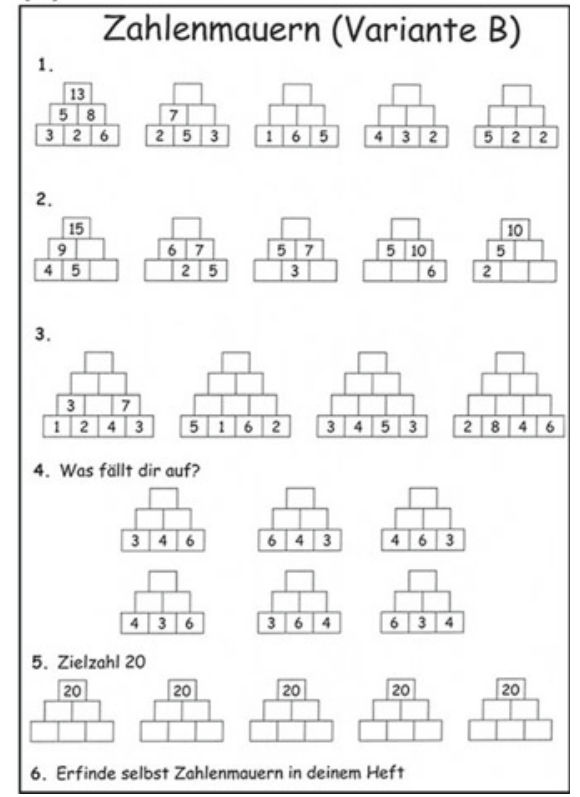

Fig. 13.8 Work sheets for number pyramids (a Translation worksheet on the left: Number pyramid (Variant A); 1. Small number pyramids; 2. Large number pyramids; 3. Difficult number pyramids; b Translation worksheet on the right: number pyramid (Variant B); 4 . What do you notice?; 5. Target number 20; 6. Make your own number pyramids in your notebook)

more than the acquisition of knowledge, such as knowing multiplication tables by heart, and skills, such as completely mastering the standard way of written addition.

\subsubsection{Mathematics, More Than Calculating}

Besides such content-related competences, German mathematics lessons are always also meant to promote process-related competences such as arguing and presenting. The added value can be illustrated by comparing two work sheets for the so-called 'number pyramids' (see Fig. 13.8). In these number pyramids, numbers are first entered into their bottom row of bricks and then the bricks above are each filled with the sum of the bricks below. Variant A only poses problems of the same type. Hence, the focus here is on practicing addition and subtraction.

The first three tasks of Variant B are also included in Variant A, but Variant B focuses on more. In Task 4 of this worksheet, the students are asked to examine the impact of the different arrangements of 3,4 and 6 on the other numbers in the pyramid. In Task 5, they are asked to create pyramids with the target number of 20 . 
And in Task 6, they are finally invited to freely invent number pyramids. This touches upon content-related as well as process-related competences.

The development of process-related competences is hence a central objective in mathematics education. It is, however, also observable that some students, for example, found it difficult to discover interdependencies between the bricks of a pyramid, describe these interdependencies or give reasons why the bricks are interdependent.

Based on these considerations, it is in our opinion essential for the design and selection of learning environments aimed at promoting process-competences as well as content-related competences that particular attention is paid to the following.

- A learning environment should be characterised by a challenging yet easily understandable problem definition(s) to ideally render the assignments accessible for every student.

- The challenging problem should lend itself to various ways of solving it (i.e., not only by means of a single approach) so that students at different levels of learning can address it in keeping with their individual skills and capabilities.

- The students should be supported to be able to adequately present their discoveries orally and in writing.

\subsubsection{Sums of Consecutive Natural Numbers}

How these principles can be implemented can be illustrated by the sample lesson titled "Sums of consecutive natural numbers" (see Schwätzer \& Selter, 1998), which core idea is to make additions of consecutive natural numbers to reach at a particular target number - a type of problem that poses challenging difficulties for students in various grades and where the five cornerstones of the principle of progressive mathematisation (see above, Streefland, 1990) are also fulfilled because

- the assignment can be realised by students

- the assignment enables learning processes moving from concreteness to abstraction

- the students are continuously stimulated to reflect on their own thought processes and those of others

- opportunities are created for communication and cooperation in small groups or whole-class discussions, and

- the assignment supports the construction of knowledge and skills into a structured entity.

An assignment that is used in 4th grade is about finding all numbers up to 25 which can be written as the sum of consecutive natural numbers (see Schwätzer \& Selter, 1998, 2000; kira.dzlm.de/171; see Table 13.3).

These numbers can be found in various ways. However, it must be noted here that the required time may vary, that not all students will be able to identify all the possible additions, and that students will initially often notate the found additions 
Table 13.3 Numbers up to 25 that can be written as the sum of consecutive natural numbers

\begin{tabular}{|c|c|c|c|c|c|}
\hline \multirow[t]{2}{*}{ Sum } & \multicolumn{5}{|c|}{ Addition with } \\
\hline & $\begin{array}{l}2 \\
\text { summands }\end{array}$ & $\begin{array}{l}3 \\
\text { summands }\end{array}$ & 4 summands & 5 summands & 6 summands \\
\hline \multicolumn{6}{|l|}{1} \\
\hline \multicolumn{6}{|l|}{2} \\
\hline 3 & $1+2$ & & & & \\
\hline \multicolumn{6}{|l|}{4} \\
\hline 5 & $2+3$ & & & & \\
\hline 6 & & $1+2+3$ & & & \\
\hline 7 & $3+4$ & & & & \\
\hline \multicolumn{6}{|l|}{8} \\
\hline 9 & $4+5$ & $2+3+4$ & & & \\
\hline 10 & & & $1+2+3+4$ & & \\
\hline 11 & $5+6$ & & & & \\
\hline 12 & & $3+4+5$ & & & \\
\hline 13 & $6+7$ & & & & \\
\hline 14 & & & $2+3+4+5$ & & \\
\hline 15 & $7+8$ & $4+5+6$ & & $\begin{array}{l}1+2+3+4+ \\
5\end{array}$ & \\
\hline \multicolumn{6}{|l|}{16} \\
\hline 17 & $8+9$ & & & & \\
\hline 18 & & $5+6+7$ & $3+4+5+6$ & & \\
\hline 19 & $9+10$ & & & & \\
\hline 20 & & & & $\begin{array}{l}2+3+4+5+ \\
6\end{array}$ & \\
\hline 21 & $10+11$ & $6+7+8$ & & & $\begin{array}{l}1+2+3+4+ \\
5+6\end{array}$ \\
\hline 22 & & & $4+5+6+7$ & & \\
\hline 23 & $11+12$ & & & & \\
\hline 24 & & $7+8+9$ & & & \\
\hline 25 & $12+13$ & & & $\begin{array}{l}3+4+5+6+ \\
7\end{array}$ & \\
\hline
\end{tabular}

in an unsystematic and spontaneous manner. Experience has shown that students proceed in ever more systematic ways, and meanwhile develop various strategies, in the course of their progressive engagement with the assignment. Table 13.4 shows the repertory of strategies observed in the students (adapted from Schwätzer \& Selter, 1998).

After finding numbers up to 25 which can be written as the sum of consecutive natural numbers, the objective now resides in checking and establishing 
Table 13.4 Strategies for finding numbers that can be written as the sum of consecutive natural numbers

\begin{tabular}{|c|c|c|c|c|}
\hline Strategy & Description & \multicolumn{3}{|c|}{ Example } \\
\hline 1. Extension at the end & $\begin{array}{l}\text { The addition is extended by the } \\
\text { consecutive summand }\end{array}$ & \multicolumn{3}{|c|}{$\begin{array}{l}3+4+5 \rightarrow 3+4+ \\
5+6\end{array}$} \\
\hline 2. Extension at the front & $\begin{array}{l}\text { The addition is extended by the } \\
\text { previous summand }\end{array}$ & \multicolumn{3}{|c|}{$\begin{array}{l}3+4+5 \rightarrow 2+3+ \\
4+5\end{array}$} \\
\hline 3. Reduction at the end & The last summand is left out & \multicolumn{3}{|c|}{$3+4+5 \rightarrow 3+4$} \\
\hline 4. Reduction at the front & The first summand is left out & \multicolumn{3}{|c|}{$3+4+5 \rightarrow 4+5$} \\
\hline 5. Increasing all & $\begin{array}{l}\text { All summands are increased by } \\
\text { one }\end{array}$ & \multicolumn{3}{|c|}{$\begin{array}{l}3+4+5 \rightarrow 4+5+ \\
6\end{array}$} \\
\hline 6. Decreasing all & $\begin{array}{l}\text { All summands are decreased by } \\
\text { one }\end{array}$ & \multicolumn{3}{|c|}{$\begin{array}{l}3+4+5 \rightarrow 2+3+ \\
4\end{array}$} \\
\hline $\begin{array}{l}\text { 7. Starting with the next natural } \\
\text { number }\end{array}$ & $\begin{array}{l}\text { The first summand is the } \\
\text { consecutive natural number of } \\
\text { the last summand from the } \\
\text { previous addition }\end{array}$ & \multicolumn{3}{|c|}{$\begin{array}{l}2+3+4 \rightarrow \text { e.g., } 5+ \\
6+7\end{array}$} \\
\hline 8. Starting with the precursor & $\begin{array}{l}\text { The last summand of the new } \\
\text { addition is the 'precursor' of the } \\
\text { previous addition }\end{array}$ & \multicolumn{3}{|c|}{$\begin{array}{l}7+8+9 \rightarrow 2+3+ \\
4+5+6\end{array}$} \\
\hline $\begin{array}{l}\text { 9. Starting with the last } \\
\text { summand }\end{array}$ & $\begin{array}{l}\text { The first summand is same as the } \\
\text { last summand of the previous } \\
\text { addition }\end{array}$ & \multicolumn{3}{|c|}{$\begin{array}{l}3+4+5 \rightarrow \text { e.g., } 5+ \\
6\end{array}$} \\
\hline 10. Starting with the addition & $\begin{array}{l}\text { The first summand is the sum of } \\
\text { the previous addition }\end{array}$ & \multicolumn{3}{|c|}{$\begin{array}{l}3+4+5 \rightarrow \text { e.g., } 12 \\
+13\end{array}$} \\
\hline $\begin{array}{l}\text { 11. Analysing the first } \\
\text { summands }\end{array}$ & $\begin{array}{l}\text { Looking for which number has } \\
\text { not been used as the first } \\
\text { summand }\end{array}$ & \multicolumn{3}{|c|}{$\begin{array}{l}3+4+5=12, \text { e.g. } \\
2+3+4=9 \\
5+6+7=18\end{array}$} \\
\hline \multirow{3}{*}{$\begin{array}{l}\text { 12. Combinations of different } \\
\text { strategies }\end{array}$} & \multirow{3}{*}{$\begin{array}{l}\text { Consecutively use of (different } \\
\text { or equal) strategies, e.g., } \\
\text { "extension at the end" and } \\
\text { afterwards "reduction at the } \\
\text { front" }\end{array}$} & & $3+$ & $4+5$ \\
\hline & & $\rightarrow$ & $3+$ & $\begin{array}{l}4+5 \\
+6\end{array}$ \\
\hline & & $\rightarrow$ & & $\begin{array}{l}4+5 \\
+6\end{array}$ \\
\hline
\end{tabular}

the completeness. Three approaches are generally observable for this. The first and most systematic strategy is starting with checking the first summand and followed by the possible number of summands $[1+2],[1+2+$ $3],[1+2+3+4, \ldots],[2+3],[2+3+4]$, etcetera). The second strategy is when students primarily focus on the number of summands and only later take into account the variable of the first summand $(1+2,2+3,3+4, \ldots, 1+2+3, \ldots)$. In this way, the focus is first on all additions with two summands, then on those featuring three, four and finally five summands. The summands can then be presented in an ascending manner (see Fig. 13.9). In the third strategy, the focus is on the results of the additions. In this strategy, the 

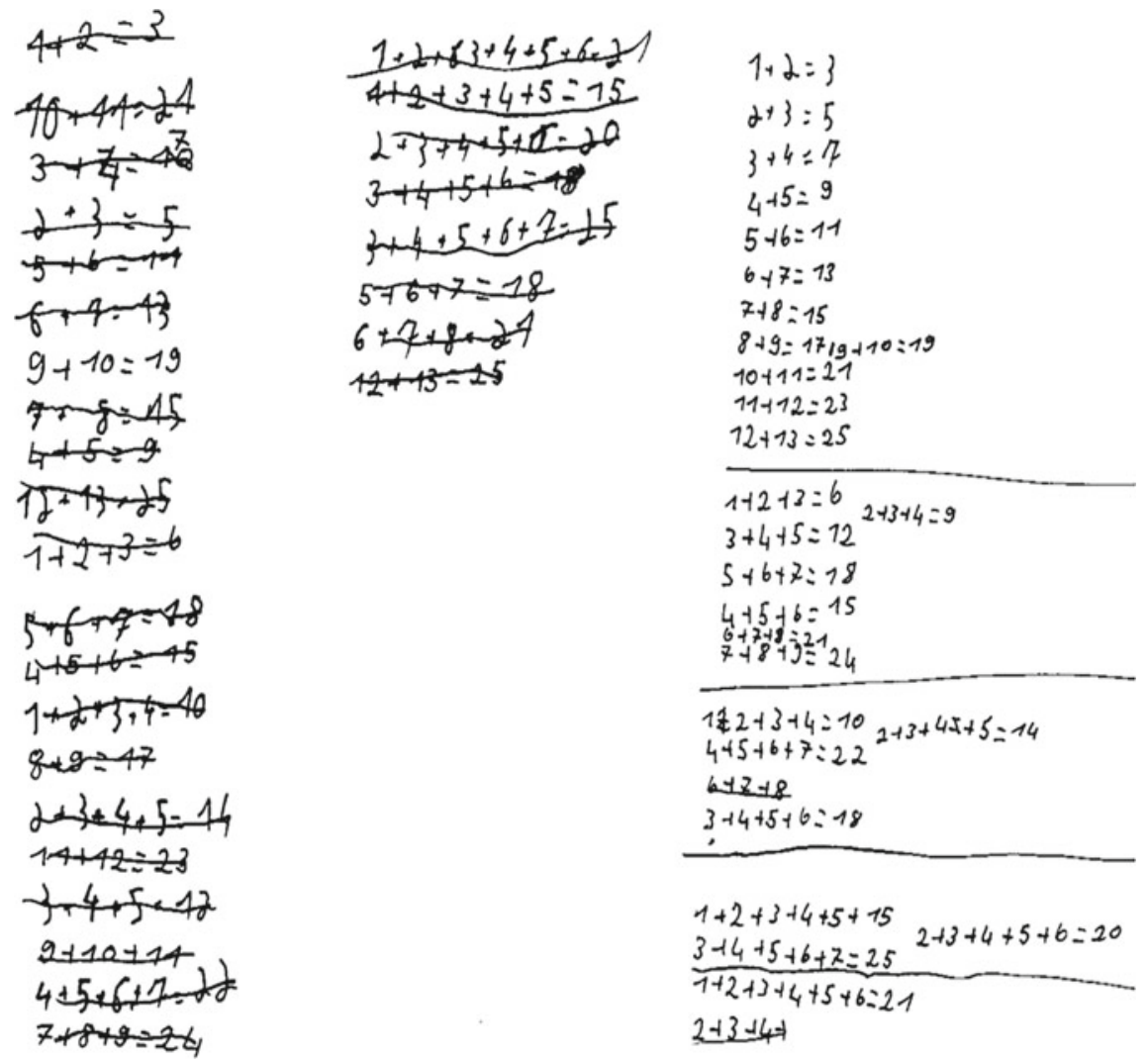

Fig. 13.9 Establishing completeness, sorted by the number of summands

students check whether each sum is reached by comparing the additions they found with the results shown in Table 13.3. This latter strategy may be effective, but cannot be considered as desirable, because the students only compare results and do not invent a systematic procedure for checking the results.

\subsubsection{Mathematics Language Tools}

A number of students will need support for describing how to find numbers that can be written as the sum of consecutive numbers and giving reason to be sure that they found them all. Even if the students are able to find all the additions and can develop a systematic approach for finding them all, this does not necessarily mean that they can always express their way of working and their 'proof' in a manner which is comprehensible to their classmates and the teacher. 


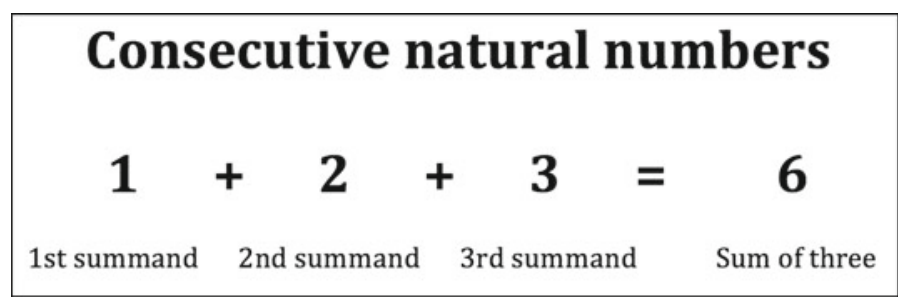

Fig. 13.10 Lexical store for working with consecutive natural numbers (translated from German by the authors)

These difficulties are normal and can, among other things, be traced back to the fact that students resort to the language they primarily use in everyday life. Just as most students will not learn multiplication tables or standard algorithms without any further support, they will also not automatically acquire competences in describing strategies and giving reasons why using this results in all possible additions.

In our opinion, it is therefore helpful to offer the students language structures in agreement with the so-called 'scaffold' approach (see for more information, Gibbons, 2002, 2006), which can serve to support the description of things they noticed (Götze, 2015). The promotion of a specific technical language can be approached at two levels. Besides the communication in the teaching situation (micro-scaffolding) is essential, elements for advancing the technical language are in the planning of the lessons (macro-scaffolding) are vital as well. The possibilities of macro-scaffolding will be addressed below by way of the sample lesson, titled "Sums of consecutive natural numbers".

Agreement on a common language is already decisive in the introductory stage. What suggests itself for this is the creation of so-called 'lexical stores' which include frequently used terms that can then be applied when working on an assignment. This is in no way meant to prescribe a normatively defined use of language to the students. The objective rather implies establishing a consensus for mutual communication that both is based on the students' previous language skills and also is technically adequate.

It is advisable for an initial orientation to name the assignments' central mathematical objects with corresponding technical terms in a joint effort with the students. Naming the objects as specifically as possible is particularly important for this. In the example shown in Fig. 13.10, simply calling the numbers to be added " 1 st, 2 nd and 3rd number" was deliberately not used, because the use of " 1 st, 2nd and 3rd summand" directly creates a closeness to the addition which is of relevance for this assignment. The same should also be considered for the sum of the addition. In line with the deliberations above, this could for example be labelled as a 'sum of three' (in German this is called 'Dreiersumme').

In building up to the terms of mathematical objects, it can also be helpful to integrate the names and anchor examples of the individual strategies step-by-step, along with formulation aids (see Fig. 13.11). 
These words can help you:

\section{Formulation aids}

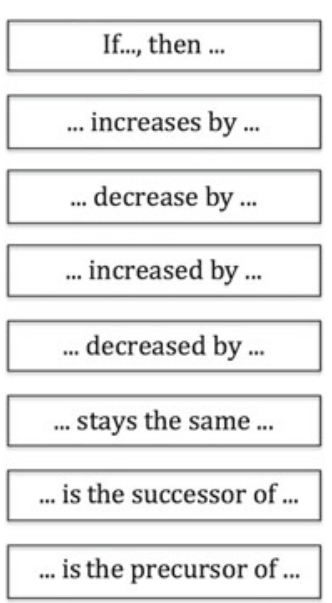

Strategy names
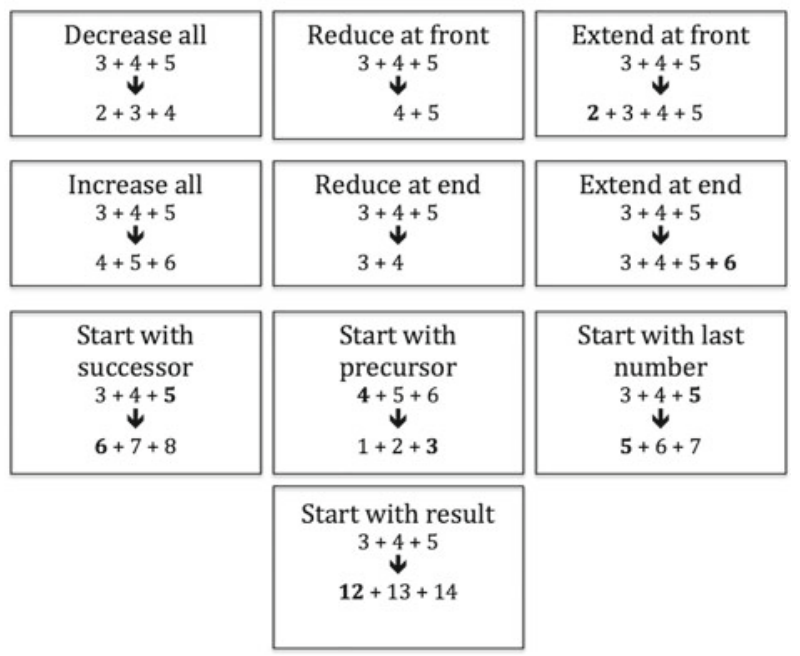

Start with last number $3+4+5$ $5+6+7$

Fig. 13.11 Formulation aids and anchor examples of strategies for sums of consecutive natural numbers (translated from German by the authors)

These formulation aids can be used to support students when they describe their discoveries and the causal relationships in technical terms. It is, for example, conceivable that a student who repeatedly applies the increase-all strategy in the addition of consecutive natural numbers with three summands initially discovers changes in the sum, and will then base his or her description on the offered mathematics language tools. This could help to establish a reason like "If all three summands are increased by 1 each, the sum of them will increase by 3." Applying the decrease-all strategy could conversely enable the statement: "The sum is decreased by 3 if every summand is decreased by $1 . "$

A further variant for promoting technical language in mathematics instruction can consist of analysing series of assignments concerning adding consecutive natural numbers and having predefined descriptions rated by the students. The example in Fig. 13.12 shows the mathematical terms required by students for being able to provide a suitable assessment.

Another option is having the students creating descriptions by their own for a series of assignments that they analyse in partner work. Further ideas for the creation and embedding of mathematics language tools can be found on the website of the PIKAS project. ${ }^{4}$ One can say in summary that the creation of a lexical store can on the one hand be helpful because the students are provided with an optional orientation for description and argumentation when working on assignments concerning the sum

\footnotetext{
${ }^{4}$ See pikas.dzlm.de/304 (website in German).
} 


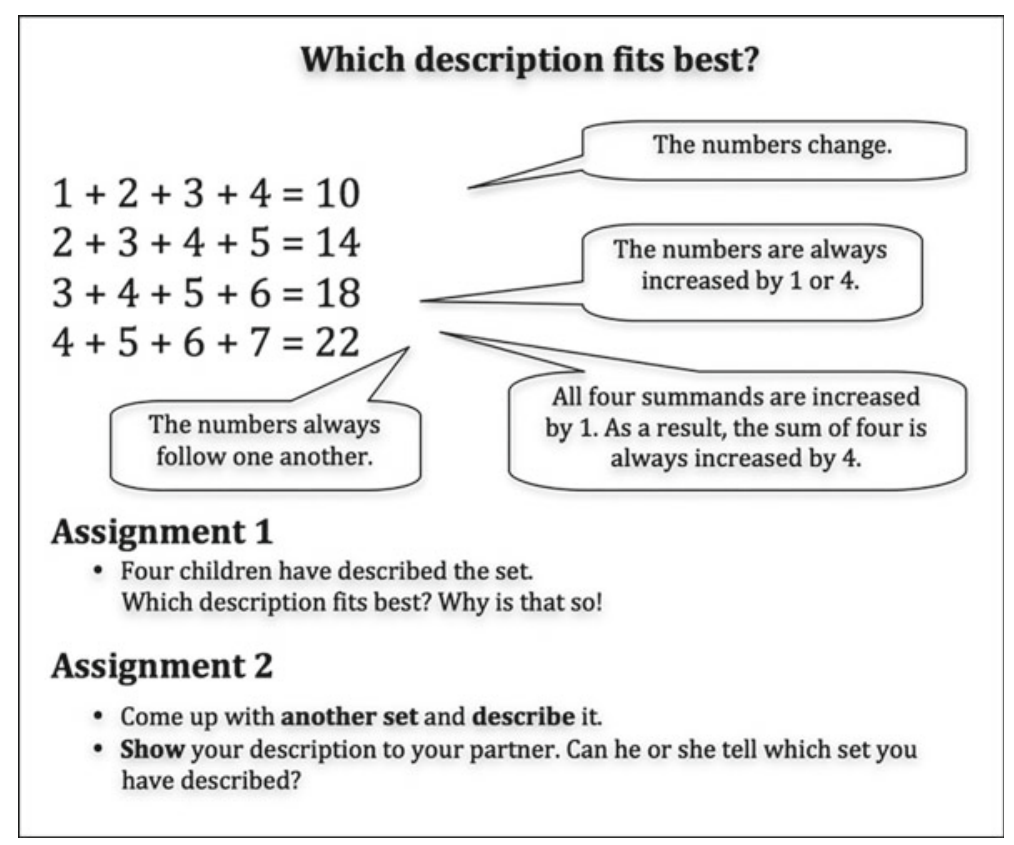

Fig. 13.12 Assigning descriptions to sums of consecutive natural numbers (translated from German by the authors)

of consecutive natural numbers. And on the other, it can also support the communication amongst the students, as well as the dialogue with the teacher. Advancing the ability to express oneself can productively stimulate the task-related exchange in the classroom.

\subsection{Numbers Can Be Realistic Too}

It may appear surprising at first glance that a book about Realistic Mathematics Education features a detailed description of two sample activities that in any way fail to refer to the real environment. A contradiction? Not at all. The reason that this is possible in Realistic Mathematics Education becomes apparent as soon as the Dutch meaning of 'realistic' is analysed. In Dutch, to realise also means 'zich realiseren' which refers to any process that can be realised in the mind (see Van den Heuvel-Panhuizen, 2002). Thus, the term does not necessarily refer to a reality in the objective sense. Instead, everything that can appear concrete and meaningful to a student is understood as realistic (see Streefland \& Treffers, 1990).

Therefore, in RME, problems presented to students can come from the real world but also from the fantasy world of fairy tales, or the formal world of mathematics, as long as the prob- 
lems are experientially real in the student's mind. (Van den Heuvel-Panhuizen \& Drijvers, 2014, p. 521)

The equal status of real-life and formal problems is also repeatedly underscored in the RME literature (see, e.g., Freudenthal 1991; Van den Heuvel-Panhuizen \& Drijvers 2014). RME is nonetheless occasionally accused of attaching greater (or a too great) value to references to real life, which means that the ideas of RME's inventors are not always adequately understood (see Van den Heuvel-Panhuizen, 2002; Wittmann, 2005).

A search for possible reasons why RME is often reduced to approximations of real contexts could rely on various explanation patterns. The name alone suggests a proximity to real-life issues in various languages, as described above. The German translation of the term 'realistic' also tends to be more signified by a relation with real life than it is the case in the Dutch language.

The mechanistic and structuralistic teaching and learning concepts so rightly criticised by RME will, at best, place references to contexts at the end of the learning process, in order to apply the structures that have been formally learned before. RME attaches a different value to the role of contexts. References to contexts are additionally characterised as starting points for the process of learning mathematics. The initially acquired 'real' models serve to support the mastery of mathematical problems on a formal and symbolic level (see Gravemeijer \& Doorman, 1999; Treffers \& De Moor, 1996; Van den Heuvel-Panhuizen 2008). To distinguish itself from traditional teaching and learning concepts, RME has attached very great importance to the doubtlessly essential meaning of references to daily life.

But the Wiskobas ${ }^{5}$ Bulletins, surely one of the sources of RME, or the publications of the TAL $^{6}$ project, for example, not only show that the vertical component is absolutely present, but also that mathematics (with no relation to reality) is regarded as a context of its own, as we tried to show in our contribution. RME could possibly highlight this aspect even more strongly.

As mentioned earlier on, what counts for students is the existence of a context that makes sense. The context does not have to be a real-life one. Pure numerical contexts can also be quite meaningful for students (e.g., Steinweg, 2001), or, to put it differently, 'numbers can be realistic, too!'

\section{References}

Akinwunmi, K. (2012). Zur Entwicklung von Variablenkonzepten beim Verallgemeinern mathematischer Muster [On the development of variable concepts in the generalisation of mathematical patterns]. Wiesbaden, Germany: Springer.

\footnotetext{
${ }^{5}$ Wiskunde op de Basisschool (Mathematics in Primary School). Wiskobas Bulletin is the journal published by the Wiskobas project from 1971 to 1981.

6 Tussendoelen Annex Leerlijnen (Intermediate Attainment Targets and Learning Lines). In the TAL project, the so-called 'teaching-learning trajectories' for primary mathematics education have been developed (see, e.g., Van den Heuvel-Panhuizen, 2008).
} 
Anders, K., \& Oerter, A. (2009). Forscherhefte und Mathematikkonferenzen in der Grundschule, $3+$ 4 [Explorer books and mathematics conferences in primary school]. Seelze, Germany: Kallmeyer.

Freudenthal, H. (1968). Why to teach mathematics so as to be useful? Educational Studies in Mathematics, 1, 3-8.

Freudenthal, H. (1991). Revisiting mathematics education. China lectures. Dordrecht, the Netherlands: Kluwer Academic Publishers.

Gibbons, P. (2002). Scaffolding language, scaffolding learning. Teaching second language learners in the mainstream classroom. Portsmouth, NH: Heinemann.

Gibbons, P. (2006). Unterrichtsgespräch und das Erlernen neuer Register in der Zweitsprache [Teaching conversation and learning new registers in the second language]. In P. Mecheril \& Th. Quehl (Eds.), Die Macht der Sprachen. Englische Perspektiven auf die mehrsprachige Schule (pp. 10-35). Münster, Germany: Waxmann.

Glade, M. (2016). Individuelle Prozesse der fortschreitenden Schematisierung-Empirische Rekonstruktionen zum Anteil vom Anteil [Individual processes of progressive schematisation-Empirical reconstructions to proportion of proportion]. Wiesbaden, Germany: Springer.

Glade, M., \& Prediger, S. (2017). Students' individual schematization pathways-Empirical reconstructions for the case of part-of-part determination for fractions. Educational Studies in Mathematics, 94(2), 185-203.

Götze, D. (2007). Mathematische Gespräche unter Kindern. Zum Einfluss sozialer Interaktion von Grundschulkindern beim Lösen komplexer Aufgaben [Mathematical talks among children. On the influence of social interaction of primary school children in solving complex tasks]. Hildesheim, Germany: Franzbecker.

Götze, D. (2015). Sprachförderung im Mathematikunterricht [Fostering mathematical language in mathematics teaching]. Berlin, Germany: Cornelsen.

Gravemeijer, K., \& Doorman, M. (1999). Context problems in Realistic Mathematics Education: A calculus course as an example. Educational Studies in Mathematics, 39, 111-129.

KMK. (2004). Bildungsstandards für das Fach Mathematik im Primarbereich [Educational standards for primary mathematics]. München, Germany: Wolters-Kluwer, Luchterhand Verlag.

Krauthausen, G., \& Scherer, P. (2007). Einführung in die Mathematikdidaktik [Introduction to didactics of mathematics]. Heidelberg, Germany: Spektrum Akademischer Verlag.

Link, M. (2012). Grundschulkinder beschreiben operative Zahlenmuster [Primary school children describe operative number patterns]. Wiesbaden, Germany: Springer Spektrum.

Schwätzer, U., \& Selter, Ch. (1998). Summen von Reihenfolgezahlen - Vorgehensweisen von Viertklässlern bei einer arithmetisch substantiellen Aufgabenstellung [Sums of consecutive natural numbers-Approaches of fourth graders with an arithmetically substantive task]. Journal für Mathematikdidaktik, 98(2/3), 123-148.

Schwätzer, U., \& Selter, Ch. (2000). Plusaufgaben mit Reihenfolgezahlen - Eine Unterrichtsreihe für das 4. bis 6. Schuljahr [Addition problems with consecutive natural numbers-A series of lessons for the 4th to 6th school year]. Mathemathische Unterrichtspraxis, 2, 28-37.

Selter, C. (1998). Building on children's mathematics-A teaching experiment in grade 3. Educational Studies in Mathematics, 36, 1-27.

Steinweg, A. S. (2001). Zur Entwicklung des Zahlenmusterverständnisses bei Kindern [On the development of children's concept of number patterns]. Münster, Germany: LIT Verlag.

Streefland, L. (1990). Free productions in teaching and learning mathematics. In K. Gravemeijer, M. van den Heuvel-Panhuizen, \& L. Streefland (Eds.), Contexts, free productions, tests and geometry in Realistic Mathematics Education (pp. 33-52). Utrecht, the Netherlands: OW\&OC, Utrecht University.

Streefland, L. (1991). Fractions in Realistic Mathematics Education. Dordrecht, the Netherlands: Kluwer Academics Publishers.

Streefland, L., \& Treffers, A. (1990). Produktiver Rechen-Mathematik-Unterricht [Productive mathematics teaching]. Journal für Mathematikdidaktik, 90(4), 297-322. 
Sundermann, B. (1999). Rechentagebücher und Rechenkonferenzen. Für Strukturen im offenen Unterricht [Math diaries and math conferences. For structures in open learning]. Grundschule, 1, $48-50$.

Sundermann, B., \& Selter, C. (1995). Halbschriftliches Rechnen auf eigenen Wegen [Informal addition and subtraction on own ways]. In G. N. Müller \& E Ch. Wittmann (Eds.), Mit Kindern rechnen (pp. 165-178). Frankfurt, Germany: Arbeitskreis Grundschule.

Sundermann, B., \& Selter, Ch. (2012). Halbschriftliches Subtrahieren auf eigenen Wegen [Informal subtraction on own ways]. In G. N. Müller, Ch. Selter, \& E Ch. Wittmann (Eds.), Zahlen, Muster und Strukturen - Spielräume für aktives Lernen und Üben (pp. 201-208). Leipzig, Germany: Klett.

Treffers, A. (1983). Fortschreitende Schematisierung. Ein natürlicher Weg zur schriftlichen Multiplikation und Division im 3. und 4. Schuljahr [Progressive schematisation. A natural way to written multiplication and division in grade 3 and 4]. Mathematik lehren, 1, 16-20.

Treffers, A. (1987). Three dimensions. A model of goal and theory description in mathematics instruction-The Wiskobas project . Dordrecht, the Netherlands: D. Reidel Publishing Company.

Treffers, A. (1991). Didactical background of a mathematics program for primary education. In L. Streefland (Ed.), Realistic Mathematics Education in primary school - On the occasion of the opening of the Freudenthal Institute (pp. 21-56). Utrecht, the Netherlands: CD- $B$ Press/Freudenthal Institute, Utrecht University.

Treffers, A. (1993). Wiskobas and Freudenthal - Realistic Mathematics Education. Educational Studies in Mathematics, 25, 89-108.

Treffers, A., \& De Moor, E. (1996). Realistischer Mathematikunterricht in den Niederlanden [Realistic mathematics education in the Netherlands]. Grundschulunterricht, 43(6), 16-19.

Van den Heuvel-Panhuizen, M. (2002). Realistic Mathematics Education as work in progress. In F.-L. Lin (Ed.), Common sense in mathematics education. Proceedings of 2001 The Netherlands and Taiwan Conference on Mathematics Education, Taipei, Taiwan (pp. 1-42). Taipei, Taiwan: National Taiwan Normal University.

Van den Heuvel-Panhuizen, M. (Ed.). (2008). Children learn mathematics. A learning-teaching trajectory with intermediate attainment targets for calculation with whole numbers in primary school. Rotterdam, the Netherlands/Taipei: Sense Publishers.

Van den Heuvel-Panhuizen, M. (2010). Reform under attack - Forty years of working on better mathematics education thrown on the scrapheap? No way! In L. Sparrow, B. Kissane \& C. Hurst (Eds.), Proceedings of the 33rd Annual Conference of the Mathematics Education Research Group of Australasia (pp. 1-25). Fremantle, Australia: MERGA.

Van den Heuvel-Panhuizen, M., \& Drijvers, P. (2014). Realistic Mathematics Education. In S. Lerman (Ed.), Encyclopedia of mathematics education (pp. 521-525). Dordrecht, the Netherlands: Springer.

Verschaffel, L., Greer, B., \& De Corte, E. (2007). Whole number concepts and operations. In F. K. Lester (Ed.), Second handbook of research on mathematics teaching and learning (pp. 557-629). Charlotte, NC: Information Age Publishing.

Wittmann, E Ch. (2005). Realistic Mathematics Education, past and present. Nieuw Archief voor Wiskunde, 5/6(4), 294-296. 
Open Access This chapter is distributed under the terms of the Creative Commons Attribution 4.0 International License (http://creativecommons.org/licenses/by/4.0/), which permits use, duplication, adaptation, distribution and reproduction in any medium or format, as long as you give appropriate credit to the original author(s) and the source, a link is provided to the Creative Commons license and any changes made are indicated.

The images or other third party material in this chapter are included in the work's Creative Commons license, unless indicated otherwise in the credit line; if such material is not included in the work's Creative Commons license and the respective action is not permitted by statutory regulation, users will need to obtain permission from the license holder to duplicate, adapt or reproduce the material. 